\title{
COMPARATIVE ANALYSIS ON MUSCLE STRENGTH AMONG PATIENTS WHO UNDERWENT ARTHROSCOPIC TENOTOMY OF THE LONG HEAD OF THE BICEPS IN RELATION TO ESTHETIC DEFORMITY
}

\author{
Alexandre Almeida', Márcio Rangel Valin', Nayvaldo Couto de Almeida' ${ }^{1}$, Gilberto Roveda' ${ }^{1}$, Ana Paula Agostini ${ }^{2}$
}

\section{ABSTRACT}

Objective: To determine whether there was any discrepancy in elbow flexion strength among patients with and without evident clinical deformity resulting from arthroscopic tenotomy on the long head of the biceps. Method: A group of 120 patients who underwent this procedure were evaluated. After applying the exclusion criteria, 89 patients remained in the analysis. Eighteen months after the operation (median), the elbow flexion strength was measured in newtons using a digital dynamometer. Three consecutive measurements were made and the average was used. The dominant and non-dominant sides were compared. Sex, age and mean elbow flexion strength in the operated and contralateral arms of patients with and without apparent clinical deformity were evaluated. Results: The median elbow flexion strength among the patients with evident clinical deformity was $17.78 \mathrm{~N}$ for the dominant arm and $20.87 \mathrm{~N}$ for the non-dominant arm. The difference was $2.51 \mathrm{~N}$. In the group without evident clinical deformity, the difference was $2.14 \mathrm{~N}$. The median muscle strength in the operated arm was $17.26 \mathrm{~N}$, while the median was $20.06 \mathrm{~N}$ in the non-operated arm, thus suggesting that there was a significant loss of muscle strength $(p=0.005)$. The difference in muscle strength loss between the patients with and without evident deformity was not considered statistically significant $(p=0.977)$. Conclusion: The patients who underwent arthroscopic tenotomy on the long head of the biceps with or without apparent clinical deformity from distal migration presented similar elbow flexion muscle strength.

Keywords - Elbow Joint/surgery; Arthroscopy; Evaluation Studies; Evaluation

\section{INTRODUCTION}

A surgical approach towards lesions of the long head of the biceps (LHB) during arthroscopy on the shoulder is indicated whenever $50 \%$ or more of the tendon thickness is found to be compromised, the biceps sulcus is unstable or a degenerative labial lesion is present in an elderly patient ${ }^{(1-3)}$.

Improvement of pain following tenotomy of the LHB has been documented by several authors, since this is an important source of pain in the joint ${ }^{(1,4-6)}$. There is concordance in the literature that LHB lesions should not be neglected, or else the final result from treating rotator cuff injuries may be impaired $^{(1-8)}$. However, tenotomy has consequences regarding upper-arm esthetics, with distal migration of the $\mathrm{LHB}^{(5,6,9)}$, loss of one of the stabilizing factors of the joint ${ }^{(7,10,11)}$ and loss of muscle strength relating to elbow flexion and supination ${ }^{(12-14)}$. Barber et al ${ }^{(15)}$ emphasized that loss of muscle strength resulting from LHB tenotomy does not affect leisure sports practices and day-to-day activities.

Walch et $a l^{(16)}$ reported that in some cases, the LHB

1 - Orthopedist in Caxias do Sul, RS, Brazil.

2 - MSc in Pediatrics from the Pontifical Catholic University of Rio Grande do Sul, RS, Brazil.

Work performed at Hospital Saúde, Caxias do Sul, RS, and in the Orthopedics Residency Service at Hospital Pompéia, Caxias do Sul, RS.

Correspondence: Rua Vitório Buzelatto 222/601, Madureira, 95020-290 Caxias do Sul, RS. E-mail: bone@visao.com.br

Work received for publication: November 20, 2011; accepted for publication: December 13, 2011.

The authors declare that there was no conflict of interest in conducting this work 
might remain fixed in the biceps sulcus following tenotomy. This could impede distal migration of the LHB, thus leaving the residual esthetic deformity of the upper arm less evident. However, their study did not report whether the muscle strength of the brachial biceps would be preserved if the LHB were to remain attached to the biceps sulcus.

The main objective of the present study was to determine whether there was any discrepancy in elbow flexion strength in the operated limb among patients undergoing LHB tenotomy between those with and without clinical deformity resulting from this procedure.

\section{METHODS}

\section{This was a cross-sectional study.}

A group of 120 patients was analyzed, who underwent shoulder arthroscopy in which tenotomy of the LHB was the main procedure or an additional one. The procedures were performed between October 29, 2002, and September 30, 2008.

All the patients studied received an informed consent statement approved by the ethics committees of the institutions where the study was conducted.

After anesthetization, the patient was positioned in lateral decubitus with the upper limb abducted at $30^{\circ}$, flexed at $20^{\circ}$ and under traction of $5 \mathrm{~kg}$. The joint distension technique used consisted of application of physiological serum in suspension for the patients operated up to May 2007, and a joint pressure pump from that date onwards ${ }^{(17)}$. Tenotomy of the LHB was performed using a trimmer forceps at the insertion in the superior labrum of the glenoid whenever the tendon thickness was found to be compromised by $50 \%$ or more, instability at the intertubercular sulcus was diagnosed or a degenerative labral lesion was found in an elderly patient. The procedure was always carried out by the same surgeon.

All the patients were immobilized using a sling, while still anesthetized in the surgical theater. An abduction pad was used when the sutured rotator cuff lesion was large or extensive. During the immediate postoperative period, the patients were advised to avoid complete extension of the elbow for six weeks, i.e. restricting their extension to no more than 30 degrees $^{(18)}$.
All patients who presented any condition that might impair assessment of the muscle strength of the contralateral upper limb were excluded from this study: complaints of pain in the contralateral shoulder (eight patients), lesions of the contralateral LHB (two patients), great pain in the operated shoulder, i.e. a poor result from the treatment performed (one patient) and antecedents of other surgical procedures or fractures in either of the upper limbs (five patients). The 15 patients whose non-dominant side was operated were also excluded from the sample.

The postoperative assessment was done after a median of 18 months (IQR: 11 to 26 months; minimum or four and maximum of 62 months). The method used was to measure the muscle strength in both upper limbs in accordance with the recommendations of the American Society of Exercise Physiology ${ }^{(19)}$. The elbow flexion strength was measured in newtons $(\mathrm{N})$ by means of a digital balance $\left(\right.$ Berkley ${ }^{\circledR}$ ) composed of two adjustable rigid loops: one attached to the patient's foot and the other to his hand. The patient remained standing, with the elbow at 90 degrees to the body and the forearm in supination. The position of maximum supination of the forearm was used as a means of evaluating the elbow flexion strength without the elbow interfering with another important function of the biceps: the function of supinator of the forearm. The device was adjusted to fit the patient's height. Three consecutive measurements were made, with a mean interval of five seconds, and the average of these was used.

The variables studied were sex, age and the average from three consecutive measurements of elbow flexion strength in the operated upper limb and contralateral limb.

The data were analyzed using SPSS (Statistical Package for the Social Sciences), version 12.0 (SPSS Inc. 1989-2003). The statistical analysis consisted of calculation of means, standard deviations, frequencies and percentages. Student's t test was used to compare the means between symmetrical variables and the Mann-Whitney test for asymmetrical variables. Differences with $\mathrm{p} \leq 0.05$ for a confidence interval of $95 \%$ were taken to be significant. 


\section{RESULTS}

The study assessed 120 patients, of whom 31 were excluded in accordance with the exclusion criteria, thus totaling 89 patients.

The mean age of the sample was $60.2 \pm 9.7$ years. Regarding sex, 28 patients were male and 61 (68.5\%) were female. The mean age of the male patients was $59.8 \pm 10.4$ years, while the mean for the females was $60.4 \pm 9.4$ years.

The group of patients with evident clinical deformity (CD) was formed by 44 individuals, with a mean age of $59.3 \pm 9.8$ years. The group of patients without evident clinical deformity (ND) was formed by 45 individuals, with a mean age of $61.1 \pm 9.6$ years. Statistical analysis using Student's $t$ test between the mean ages of the two groups demonstrated that they were homogenous $(\mathrm{p}=0.374)$.

The distributions of the measurements between the operated upper limb (dominant) and nonoperated limb (non-dominant) were compared in the CD group. For the dominant arm, the median was $17.7 \mathrm{~N}$ (IQR: 13.4 to 24.7 ); and for the nondominant arm, the median was $20.8 \mathrm{~N}$ (IQR: 16.2 to 26.2). The difference in muscle strength was $2.51 \mathrm{~N}$ (IQR: -1 to 5.5 ).

The distributions of the measurements between the operated upper limb (dominant) and non-operated limb (non-dominant) were compared in the ND group. For the dominant arm, the median was $16.7 \mathrm{~N}$ (IQR: 13.8 to 21.5 ); and for the non-dominant arm, the median was $19.8 \mathrm{~N}$ (IQR: 16.2 to 26.1). The difference in muscle strength was $2.14 \mathrm{~N}$ (IQR: 0.4 to 4.3 ).

The median muscle strength in the operated upper limb was 17.2 (IQR: 13.7 to 24.1 , while the median in the non-operated limb was 20 (IQR: 16.2 to 26.1). Comparing the operated and non-operated arms of the whole sample, there was a significant loss of muscle strength according to the Mann-Whitney test $(\mathrm{p}=0.005)$.

The difference in loss of muscle strength between the patients in the CD and ND groups was not considered to be statistically significant according to the Mann-Whitney test $(\mathrm{p}=0.977)$.

\section{DISCUSSION}

Three types of lever are known: class one, like the blades of scissors; class two, like a wheelbarrow or nutcracker; and class three, like tweezers or pincers. The upper limb makes movements in accordance with the principles of how levers function, and simultaneously provide examples of class one and class three levers ${ }^{(20)}$.

A lever is basically a rigid rod fixed to a support point. The point on which it is supported is called the fulcrum. The distance from the fulcrum to the point at which the traction force is applied (power) is called the power arm, while the distance between the fulcrum and the point at which the resistance force is applied is called the resistance $\operatorname{arm}^{(20)}$.

One of the functions of the brachial biceps is to flex the forearm. The application point of the resistance is in the hand, while the fulcrum is formed by the elbow (resistance arm). The power arm is the distance from the elbow joint to the point of distal insertion of the brachial biceps. This mechanism characterizes a class three lever ${ }^{(20)}$.

In this type of lever, for equilibrium to be maintained, the most important force is power (Figure 1), given that when multiplied by the small value of the power arm, this should balance the resistance multiplied by the long resistance $\operatorname{arm}^{(20)}$.

Tenotomy of the LHB at the superior labrum of the glenoid makes an anatomical modification in which there is a change in the origin of the power force vector (Figure 1), and this may lead to changes in the muscle capacities (peak torque) of the groups involved $^{(10,21)}$.

Some authors have measured the loss of muscle strength of the brachial biceps in their samples, such as Mariani et al ${ }^{(22)}$, who compared 26 patients undergoing surgical repair of a torn LHB with 30 patients undergoing conservative treatment. They found that the group with conservative treatment lost $21 \%$ of their supination strength and $8 \%$ of their elbow flexion strength, while the group with surgical treatment did not present loss of strength. Maynou et al $^{(13)}$ examined a series of 38 patients (40 shoulders) with rotator cuff injuries who underwent arthroscopic tenotomy of the LHB and measured the elbow flexion strength. They found that there was a $40 \%$ loss of elbow flexion and supination 

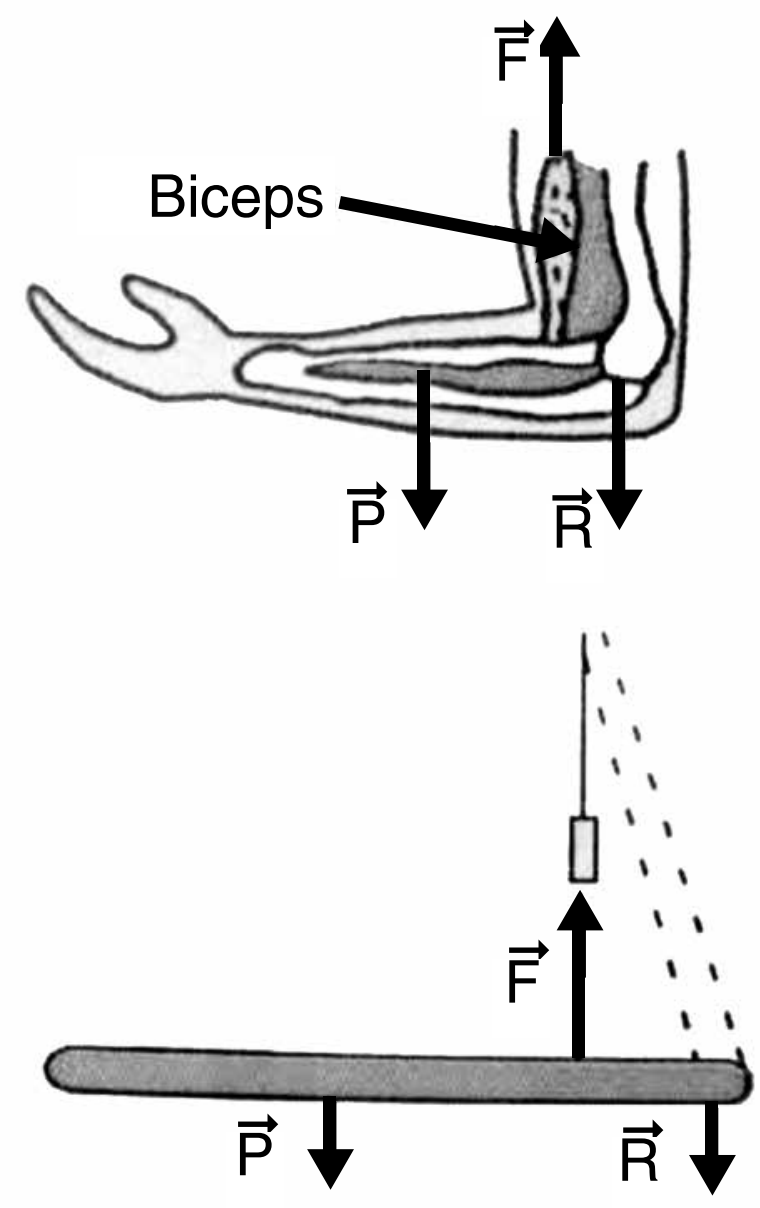

Figure 1 - Lever.

$\mathrm{P}=$ weight of the combination, $\mathrm{F}=$ force/strength, $\mathrm{R}=$ reaction of the elbow(20).

strength, in comparison with the normal rotator cuff of the control group. Almeida et al $l^{(14)}$ found a $13 \%$ loss of elbow flexion strength following arthroscopic tenotomy of the LHB, comparing the operated side with the contralateral side and with a control group. None of these authors made any correlation between losses of muscle strength that might be greater or smaller according to the esthetic deformity of the arm.

Authors like Boileau et $a l^{(8)}$ also made investigations on the loss of muscle strength following tenotomy of the LHB, but used indirect measurements such as the Constant score instead of biomechanical tests. These authors found, in their study on 68 patients ( 72 shoulders) with extensive rotator cuff injuries, that among the patients who underwent arthroscopic tenotomy of the LHB, muscle strength was the only variable that demonstrated worsening after the operation.

Walch et $a l^{(16)}$ reported that in some situations following tenotomy of the LHB, this could become attached in the biceps sulcus instead of migrating freely to the proximal third of the upper arm. This phenomenon might occur due to three factors: firstly, the fact that the biceps tendon has a greater diameter in its intra-articular portion $(8.5 \mathrm{~mm} \times 7.8$ $\mathrm{mm})$ than in the portion of the intertubercular sulcus ( $4.7 \mathrm{~mm} \times 2.6 \mathrm{~mm})$; secondly, the fact that the biceps tendon is intra-articular but extrasynovial, such that during its retraction, the synovial sheath helps in attaching it at the sulcus; and thirdly, the tendon link (a branch of the anterior circumflex artery) may help to hold back distal migration of the LHB following tenotomy.

When the LHB remains trapped in the biceps sulcus, the esthetic deformity is minimized. We did not find any studies in the literature that investigated whether this particular feature would have the capacity to partially or fully maintain the muscle strength of the brachial biceps.

We found that the patients without evident esthetic deformity from distal migration of the LHB, in whom it may be supposed that the LHB remained trapped in the biceps sulcus, did not present preserved flexion strength of the brachial biceps $(p=0.977)$.

For our study, we used a clinical criterion (presence or absence of deformity of the operated arm) in order to compare the groups. We believe that an imaging examination for documenting the fixation of the LHB in the biceps sulcus that was described by Walch could make the analysis more precise.

\section{CONCLUSION}

The patients who underwent arthroscopic tenotomy of the LHB with or without apparent clinical deformity from distal migration presented similar muscle strength for elbow flexion.

\section{ACKNOWLEDGEMENTS}

We thank Dr. José Márcio de Freitas for his suggestions and collaboration. 


\section{REFERÊNCIAS}

1. Boileau P, Krishnan SG, Coste JS, Walch G. Arthroscopic biceps tenodesis: a new technique using bioabsorbable interference screw fixation. Arthroscopy. 2002;18(9):1002-12.

2. Sethi N, Wright R, Yamaguchi K. Disorders of the long head of the biceps tendon. J Shoulder Elbow Surg. 1999;8:644-54.

3. Richards DP, Burkhart SS. A Biomechanical Analysis of Two Biceps Tenodesis Fixation Techniques. Arthroscopy 2005;21:861-6.

4. Refior HJ, Sowa D. Long tendon of the biceps brachii: sites of predilection for degenerative lesions. J Shoulder Elbow Surg. 1995;4(6):436-40.

5. Ahmad CS, EIAttrache NS. Arthroscopic biceps tenodesis.Orthop Clin North Am. 2003;34(4):499-506.

6. Kelly AM, Drakos MC, Fealy S, Taylor SA, O'Brien SJ. Arthroscopic release of the long head of the biceps tendon: functional outcome and clinical results. Am J Sports Med. 2005;33(2):208-13.

7. Checchia SL, Doneux PS, Miyazaki AN, Fregoneze M, Silva LA, Oliveira FM, et al. Tenotomia artroscópica do biceps nas lesões irreparáveis do Manguito rotador. Ver Bras Ortop. 2003;38(9):513-21.

8. Boileau P, Baqué F, Valerio L, Ahrens P, Chuinard C, Trojani C. Isolated arthroscopic Biceps tenotomy or tenodesis improves syntoms in patients with massive irreparable rotator cuff tears. J Bone Joint Surg Am. 2007;89(4):747-57.

9. Verma NN, Drakos M, O'Brien SJ. Arthroscopic transfer of the long head biceps to the conjoint tendon. Arthroscopy. 2005;21(6):764.

10. Walch G, Nové-Josserand L. Tendão da cabeça longa do biceps. In: Clínica Ortopédica: atualização em cirurgia do ombro. Rio de Janeiro: Medsi. 1999. p. 1-17.

11. Ferreira AAF. Síndrome do impacto e lesão do manguito rotador. In: Clínica Ortopédica: atualização em cirurgia do ombro. Rio de Janeiro: Medsi. 1999, p. 117-26.

12. Gill TJ, Mclrvin E, Mair SD, Hawkins RJ. Results of biceps tenotomy for treat- ment of pathology of the long head of the biceps brachii. J Shoulder Elbow Surg. 2001;10(3):247-9.

13. Maynou C, Mehdi N, Cassagnaud X, Audebert S, Mestdagh H. Clinical results of arthroscopic tenotomy of the long head of the biceps brachii in full thickness tears of the rotator cuff without repair: 40 cases. Rev Chir Orthop Reparatrice Appar Mot. 2005;91(4):300-6.

14. Almeida A, Valin MR, Roveda G, Almeida NC, Agostini AP. Avaliação da força de flexão do cotovelo após a tenotomia artroscópica da cabeça longa do bíceps. Rev Bras Ortop. 2007;42(11/12):367-72.

15. Barber FA, Byrd JW, Wolf EM, Burkhart SS. How would you treat the partially torn biceps tendon? Arthroscopy. 2001;17(6):636-9.

16. Walch G, Nové-Josserand L, Boileau P, Levigne C. Subluxations and dislocations of the tendon of the long head of the biceps. J Shoulder Elbow Surg. 1998;7(2):100-8.

17. Almeida A, Agostini AP, Valin MR, Martins JA, Ferreira R. Artroscopia do ombro com infusão de soro fisiológico em suspensão. Estamos trabalhando de forma segura? Rev Bras Ortop. 2006;41(7):253-8.

18. Godinho GG, Freitas JMA, Leite LMB, Pina ERM. Lesões SLAP no ombro. Rev Bras Ortop. 1999;43(5):211-6.

19. Brown L, Weir J. Recomendação de procedimentos da Sociedade Americana de Fisiologia do Exercício (ASEP) I: avaliação precisa da força e potência muscular. R Bras Cir Mov. 2003;11(4):95-110.

20. Paraná DNS. Física mecânica. 7a. ed. São Paulo: Editora Ática; 2000.

21. Criscuolo E, Pinto SS, Pugliese G, Oliveira C. Torque da musculatura rotadora de ombro na pós-cirurgia de Bristow. Rev Bras Ortop. 2000;35(11/12):452-6.

22. Mariani EM, Cofield RH, Askew LJ, Li G, Chao EY. Rupture of the tendon of the long head of the biceps brachii. Surgical versus Nonsurgical treatment. Clin Orth Relat Res. 1998;(228):233-9. 